DOI: $10.1515 /$ ausfm-2015-0028

\title{
Moving Picture, Lying Image: Unreliable Cinematic Narratives ${ }^{1}$
}

\author{
Tamás Csönge \\ University of Pécs (Hungary) \\ E-mail: csongetamas@gmail.com
}

\begin{abstract}
By coining the term "unreliable narrator" Wayne Booth hypothesized another agent in his model besides the author, the implicit author, to explain the double coding of narratives where a distorted view of reality and the exposure of this distortion are presented simultaneously. The article deals with the applicability of the concept in visual narratives. Since unreliability is traditionally considered to be intertwined with first person narratives, it works through subjective mediators. According to scholarly literature on the subject, the narrator has to be strongly characterized, or in other words, anthropomorphized. In the case of film, the main problem is that the narrator is either missing or the narration cannot be attributed entirely to them. There is a medial rupture where the apparatus mediates the story instead of a character's oral or written discourse. The present paper focuses on some important but overlooked questions about the nature of cinematic storytelling through a re-examination of the lying flashback in Alfred Hitchcock's Stage Fright. Can a character-narrator control the images the viewer sees? How can the filmic image still be unreliable without having an anthropomorphic narrator? How useful is the term focalization when we are dealing with embedded character-narratives in film?
\end{abstract}

Keywords: unreliable narrator, cinematic narrative, mediation, focalization, Alfred Hitchcock.

\section{The Lie (the Issue of Unreliability)}

Alfred Hitchcock's Stage Fright (1950) is a curious film, which utilizes a so called unreliable narrator, a character narrator whose story turns out to be inconsistent with the diegetic truth. The flashback scenes from Stage Fright have become the number one case study for illustrating the issues of unreliable cinematic narration.

1 This research was supported by the European Union and the State of Hungary, co-financed by the European Social Fund in the framework of TÁMOP 4.2.4. A/2-11-1-2012-0001, National Excellence Programme. 
But more importantly, it raises some basic questions about cinematic storytelling and the nature of character narrators. ${ }^{2}$ In this movie, Johnny, a character narrator is not just distorting the truth, but he is downright telling a lie for his own interest. With the analysis of this lying narrative I hope to shed some light on the concept of narrator and mediation through certain (often misunderstood) features of cinematic storytelling. The problem is quite complex because although one wishes to come up with a universal theory of the narrative, still one cannot ignore the specificities of the medium. That is why it is often hazardous to mechanically utilize models of character narration and unreliability which are mainly deduced from verbal or literary discourses in classical narratology. But another great temptation for scholars when dealing with cases like the present one is to over-concentrate on the differences and ignore some serious similarities between literary and cinematic narration that can be found on a more abstract level. Hence, this paper attempts to focus on the formal, synthetic aspects of the problem. I would like to demonstrate that character narrators can still be considered as narrators and have as much power as any literary narrator over the discourse in spite of the asymmetry of the non-anthropomorphic framing narration and a character's verbal discourse in film.

The movie begins with the scene of a woman and a man (Eve and Johnny) in a car, who are fleeing from the police. Eve asks Johnny to tell her what exactly happened, why he is trying to escape the law. The man starts to tell the story in which he got into trouble because of his lover, the famous actress, Charlotte Ingwood, who asked for his help in a murder. "I was in my kitchen, it was about five o'clock. The doorbell rang and I went downstairs to see who it was" - says Johnny, while images corroborating this verbal narration begin to appear in the movie. Here the viewer witnesses all the indicators of a typical technique of the classical style: this is the subjective flashback. Charlotte, Johnny's mistress is standing in the door in a bloodstained dress and asking him to fetch her a clean one from her apartment, where she killed her violent husband. Complying with Charlotte's request, we see Johnny entering the apartment, discovering the dead husband's body on the floor and trying to disguise the murder as a burglary. The long flashback continues up until the point where the movie began, but later, the sequence turns out to be a lie regarding the central plot element. In the last scene of the movie, Johnny confesses the murder to Eve. It was him, not his mistress

2 The whole reasoning of the present paper, especially observations concerning the narrator, are inspired by the principles articulated in Richard Walsh's paper Who is the Narrator? (1997) and his book The Rhetoric of Fictionality: Narrative Theory and the Idea of Fiction (2007). 
who killed the husband. This kind of deception was unconventional at the time Stage Fright was released, and Hitchcock himself said it was a mistake to trick his audience this way.

Most interpreters tried to properly characterize this phenomenon by using the term "unreliable narration." In its narratological sense, only fictional narration can be unreliable, a documentary or a real person cannot because (as explained by Wayne Booth, who coined the term in 1961) the audience should be able to recognize not only the purpose of the fictional utterance but another rhetorical act as well, an authorial intention behind it. Booth's famous formulation of the concept is the following: "I have called a narrator reliable when he speaks for or acts in accordance with the norms of the work (which is to say, the implied author's norms), unreliable when he does not" (Booth 1983, 158-159). Unreliability is the field of two different rhetorical goals: in this case, Johnny's intention to tell a lie and convince Eve of his innocence, and the author's intention to debunk his story as a lie. If the recognition of the latter intention is available only later, we can talk about a deceptive narrative or, in commonly used cinematic terms, a twist ending.

The question on which opinions are most divided is the attribution of this unreliability. Who is responsible for the lie in narratological terms: the character of Johnny or the non-anthropomorphic cinematic narrator? Can a character narrator control the images we see? Where can we localize the source of this unreliability and why is this important? Or simply put, the underlying question is this: who is the narrator of the lying flashback? This issue gained much attention most likely because it raises more fundamental questions about film narration: about the workings of cinematic unreliability, its differences from literary models and theories, and the question whether these differences can be derived from medial features only. Can we attribute unreliability to a non-anthropomorphic and non-characterized narrator? At this point, to clarify my stance on the subject, I cite Emily R. Anderson, who identified cinematic narrators as a complex mechanism, "the combination of cinematography, editing, mise en scène, and sound," following Chatman's definition of a film's narrator, who "cannot be made into a persona, and it cannot arise from a character within the diegesis" (Anderson 2010, 83). The present argument intends to challenge this latter part of the quotation and dispute that a character can possess narratorial qualities if the aforementioned combination of elements are understood as rhetorical acts. 


\section{Who Is in Charge? (The Issue of Narrative Power)}

First, it is to be discussed how theorists tried to answer these questions and what presuppositions can be diagnosed in their opinions. Basically, there are two approaches regarding the source of deception. One of these states that Johnny's character is responsible for the lies presented in the film. According to Seymour Chatman, not "the camera narrates the false sequence on its own. Rather, everything that we see and hear follows Johnny's scenario. Thus, even when his voice-over falls silent, he remains the controlling, if unreliable, narrator of the flashback" (Chatman 1990, 131-132). Chatman continues confidently: "at the narrative level, Johnny and Johnny alone 'produces' the segment in any narratologically meaningful sense of that word, since every cinematic tool - editing, lighting, commentative music - works to actualize his lie. During these scenes, Johnny prevails over the cinematic narrator. He is 'responsible' for the lying images and sounds that we see and hear" (Chatman 1990, 132, my emphasis).

In her 1989 book, Flashbacks in Film, Maureen Turim basically states the same: "if this flashback is a lie, - she says - its lie is Johnny's. The flashback is truthful to Johnny's narration" (Turim 1989, 166, my emphasis). But there is an important difference here, since the keyword being truthful, and not produces, prevails or responsible. Therefore, she is a bit more nuanced in her opinion and concludes that: "the film, while never itself lying, deceives its audience by conforming in its filmic means of expression to the interwoven fabric of Johnny's subjective account, and, in addition, lending it the assumed truth value of the filmic image" (Turim 1989, 167).

Robert Burgoyne builds on the concept of "impersonal narration," borrowed from Marie-Laure Ryan, and says that a narrator without personality "cannot lie about the fictional world, although the narrator can withhold information and cause the spectator to make incorrect inferences" (Ryan 1990, 7). Clearly, this is the case in films like The Beautiful Mind (Ron Howard 2001) or The Sixth Sense (M. Night Shyamalan 1999), where the narration does not misreport events but simply underreports them. The implication for him is that "lying narration in film can only be engendered by the discourse of a personal, character narrator" (Ryan 1990, 7). Burgoyne argues that the wide range of cinematic resources are not reserved exclusively for the impersonal narrator. "The unreliable character narrator can utilize images as well as words, as seen in Stage Fright" (Burgoyne 1990, 7) - he claims.

On the other end of the theoretical spectrum, researchers tend to think that cinematic narration has a greater role in deception. David Bordwell states about 
Hitchcock's film that: "it is not just the character's yarn that is unreliable. The film's narration shows itself to be duplicitous by neglecting to suggest any inadequacies in Johnnie's account and by appearing to be highly communicative - not just reporting what the liar said but showing it as if it were indeed objectively true" (Bordwell 1985, 61, my emphasis). Hence the narrative is not mysterious, but deceptive. Bordwell undoubtedly touched upon something important here: even Chatman agrees that "the camera collaborates with, subserves the narrator by misrepresenting, 'mis-showing,' the facts of the case" (Chatman 1985, 131, my emphasis) or as it were, it duplicates the rhetorical act of the diegetic narrator in the axis of communication between the film and its audience. But Bordwell goes on: "as Edward Branigan has demonstrated, such personified narrators are invariably swallowed up in the overall narratorial process of the film, which they do not produce" (Branigan 1985, 61).

Gregory Currie goes even further in his argument against Chatman's view: "Johnny, like the other characters, exists within the story, and it is no part of that story that he produced and edited cinematic images in order to convince his fictional fellows (and us?) of his innocence -anyway a transparently self-defeating enterprise" (Currie 1995, 27, my emphasis). In accordance with Currie, Anderson claims in her article that "a viewer might understand a flashback as arising from a character's point of view, but would never assume that the character had actually put the clip together." And she argues that it is "the narrator, who alone can present events to the viewer" (Anderson 2010, 85), and characters cannot be cinematic narrators because "theirs may be the points of view to which we are privy, but they cannot communicate to us. They may see, but it is the cinematic narrator who speaks, as it were, who presents" (Anderson 2010, 88).

\section{Aspects of Mediation (the Issue of Technicality)}

In my view, fictional narratives do not simply represent communicative acts, but they realize them as well. They are not "pretended assertions" as Searle calls them in a revision of speech-act theory (Searle 1975, 324), but they create a communicational situation between author and audience. My main focus is on the elements indispensable for the act of mediation due to their certain qualities. I want to draw a basically dual conceptual distinction based on the italicized expression and examine the ideas this expression refers to.

Because theorists failed to differentiate between the rhetorical and the technical aspects of mediation (which is one of the most important functions in narration), 
they are struggling with inappropriate questions like how a character can edit a sequence. The discrimination sketched in the following is a line between the abstract activities of semiotic articulation (rhetorical level) and the tools of conceptual and physical realization (technical level).

Many of the expressions used to describe the activities of the narration (like: produce, actualize, show, edit, put the clip together) are inappropriate terms in their context for analyzing the operation of the agents of mediation. They only make sense when they are referring to the physical activities of real-world entities or processes, like the actions of the makers or the performance of technological equipment. They can be used in narratological analysis, but only with increased awareness, often metaphorically. The coding and materiality of the narrative has nothing to do with the diegesis, nor with the communication between author and recipient, which process still belongs to the rhetorical level. ${ }^{3}$ In literary fiction, the nexus between these two levels is often completely transparent and continuous: the narrators of Daniel Defoe's Moll Flanders (1722) or Charles Dickens's David Copperfield (1850) are writing their own life stories and the form of the literary representation of their discourse is substantially identical with their diegetic product. They are the narrators of their stories and authors of their books: we can read exactly the same sentences they wrote down in the fictional world. The real authors remain silent and, so to speak, quote them. The difference lies in the code of fictionality: the protagonists wrote autobiographies and the recipients read novels. Even if the speaker in a literary diegesis (the character narrator) produces a verbal discourse (like in Albert Camus's The Fall), what we perceive in the representation as a textual form seems just slightly different and easily reconvertible in our minds. The technique is conventionalized to a degree that the shift is inconspicuous and seldom detected because the readers are much accustomed to it.

In films, this distance between the rhetorical and technical aspects is more obvious, more evident, the technical side being more dominant. At least in fictional narratives, there is always (to use Monika Fludernik's terminology) a duality between the "mediating function of consciousness" (Fludernik 1996, 36) and material mediation. When one speaks about the activities of the cinematic narrator, one still thinks of an abstract entity, an organizing principle which can do the editing and the adding of a soundtrack not because of the physical apparatus available to him, but because it performs symbolic acts, it is primarily

3 According to Bordwell, not all narration is communicative (Bordwell 1985, 64), but I think all fictional (literary) narratives are. 
sense-making, cognitive construction, and not the bricolage of an artefact. Even if the character cannot "actually put the clip together," this does not make them less capable on the rhetorical level to be a narrator in a story; so these are bad arguments against the narratorial qualities of character narrators because they conflate these two sides. The medium-specific problem with narrative films is that, because of some evident mimetic traditions of the genre, the characters do not have the ability to literally mediate audiovisuals, only the cinematic narrator is capable of performing this. But even when one tries to describe the activity of this agent, one shouldn't confuse its abstract function with the actual, physical realization of the work.

Even if a film has multiple narrative levels, and some (or all) of these levels have a character narrator, I consider the agent making each level "cinematic" (instead of separate cinematic narrators) more like the same authorial force, supplementing the characters' narrations. What makes these narratives "cinematic" are the tools the author uses as rhetorical resources to present someone's story directly or indirectly.

The filmic devices of the lying flashback obviously overwrite the character's narration, who (both as teller and protagonist of the story) is incapable of communicating with images. The framing (cinematic) narration quotes the character narrator directly only in the transition from one narrative level to another (the simultaneous application of verbal and visual narration is the marker of this transition), then represents his utterance by means of its own medial resources. The author had the opportunity to show the act of lying mimetically, without images, hence it is a rhetorical choice in itself to reduplicate the character's own rhetorical act: lying. It means that the lie (with the aim of deceiving the communication partner about the truthfulness of certain events) functions in two different levels at the same time. In the diegesis, the object of the persuasion is another character, Eve, who only hears the story and is fooled because of her poor judgement of Johnny's personality. At the level of discourse, it is the film's audience who believe the lie for substantially different reasons.

In the case of the flashback, one must differentiate not just between Johnny, the narrator character in the diegesis and the agency of film narration, but take a third element into consideration. Of course, the film itself was assembled by an extrafictional agent (what I would call its author) who, in a manner of speaking, can rhetorically put the clip together (notice that we are still at a metaphorical level here) but not without the tools needed for the realization of the artwork. It would be a mistake to forget that this is another sense of the word mediation, associated with 
the materials that cater this function and closely related to the medium. Even though it is only connected to narrative consciousness or agency as raw material, technical mediation is frequently blurred with rhetorical devices in narrative analysis.

\section{The Code (the Issue of Materiality)}

Let us turn our attention to this element often transparent in literature, but quite perceptible in film due to its technical equipment (apparatus). Here, our first concern is a very fundamental one. The material dimension which provides the instruments for narrative communication is often confused with an element which is only partly material: an essential aspect of mediation called code by Roman Jakobson and W. J. T. Mitchell. The latter wrote about the origins of the concept supposedly already present in Aristotle's Poetics: “Aristotle says that representations differ from one another in three ways: in object, manner, and means. The 'object' is that which is represented; the 'manner' is the way in which it is represented; the 'means' is the material that is used. What I am calling 'codes' here are basically the same thing as Aristotle's 'means' - that is, language, musical forms, paint" (Mitchell 1995, 13). But Mitchell is not very precise when he makes an equation between these two terms. Code has a more subtle meaning; to use the Saussurian terminology: it signifies the form, not the substance. Therefore, it is slightly misleading to use the two concepts as synonyms because code is a lot more abstract than the material that is used for creating a representation. It is not a physical-material object but a conceptual entity which is called the sign vehicle by Saussure. It is an abstract system rather than a sensual, palpable, visible or audible material manifestation. Nonetheless, the artefacts constructed out of these systems must take on a material form, that is, they must gain some sort of physical presence as they become artistic or simply communicational utterances.

The two aspects of mediation that has been distinguished previously could be understood as answers to the questions: "who mediates?" and "what mediates?" Narrative representation consists of the co-operation of these two, practically inseparable sides: on the one hand the activity of abstract agents linked to the rhetorical side (character narrator, cinematic narrator), on the other hand the conceptual tools (the code of the medium) and their material realization (the artefact) are both essential for the narrative to be established.

Two remarks can be made regarding the function of the classic narrator figure. It would be pointless either to assign him as a sense-making agent to the mediating capacities of the code or to equate the narrator with this aspect of the code. The 
narrator is not even the agent who facilitates the tangible realization of the code because it is a discursive concept, not an actor of the real world. This is the reason why it would be wrong to hold a character narrator in a movie accountable for this process (the material realization) saying that he "alone 'produces' the segment in any narrato-logically meaningful sense of that word, since every cinematic tool - editing, lighting, commentative music - works to actualize his lie" (Chatman 1990, 132). When Currie argues that Johnny could not be the real narrator of the lying sequence because he, "like the other characters, exists within the story, and it is no part of that story that he produced and edited cinematic images in order to convince his fictional fellows (and us?) of his innocence," he confuses the narrator's role either with that of an extrafictional agent's, who is responsible for the physical realization of the flashback, or with the author's, whose decisions define the representational mode of the work.

\section{Two Assumptions about Cinematic Character Narrators}

Johnny is a character narrator whose natural discourse is presented to the viewer indirectly, through artificial (conventional), filmic means. Both Johnny and the cinematic narrator are important for the complexity of the sequence and the filmic layer - as I argued before -; they are not just a technical necessity.

I have two assumptions regarding the flashback: (1) the character is a fullvalue narrator (despite the fact that his discourse is mediated through film) and at the same time (2) the cinematic narration has a significant rhetorical impact on the discourse. It is possible for the film to represent Johnny's narration and supplement it with additional meaning because of the medial difference between the two narrations, and the capacity of cinema to simultaneously utilize multiple channels of communication to construct its narrative.

\section{Proving the First Assumption}

One could argue that characters cannot be considered as real narrators in a film because they cannot utilize audiovisuality in the way cinematic narration does. Is Johnny really a narrator in this movie, even if cinematic codes were superimposed over his verbal narration? Can we regard the flashback as Johnny's account of the events? Despite the medial difference, I think we can, because every fictional narration is a representation and every embedded narration is also a representation of narration. Two different kinds of codes operate, and the discursive textual one 
superimposes on the thematic, verbal one. One should not forget that narrators are able to mediate their stories not because they are literally in possession of the tools that can produce the perceivable material codes or physical form of a representation, but because of a rhetorical act from the (implicit) author.

Johnny is an embedded narrator, situated inside the diegesis, and that is why he cannot communicate with the film's (implied) audience, not because he is "only a character," ontologically inferior to the cinematic discourse and thus not capable of editing, showing images or producing sound. The problem is not with his potentials as a storyteller but with his position. That is why I hypothesize a model where narrators like him cannot accost us directly; hence their lie would remain only a diegetic one, while the framing cinematic narration is transforming it (by performing a rhetorical act) to sound and images. And as a rhetorical act, the narration of the primary visual diegesis could still do this transformation if there were a personified character narrator. There are movies where a fictional character is directly addressing his extradiegetic narratee (who is the closest thing to the real audience a fictional narrator can address; moreover, the recognition of this similarity is exactly the point of the rhetorical act behind the narrator's action) and could create a more absurd scenario like in Fight Club (David Fincher, 1999) or American Beauty (Sam Mendes, 1999). The important difference that makes the character narrators' apostrophés credible is that they occupy a similar position as the viewer. Think of the voice of the deceased Lester Burnham's character (played by Kevin Spacey) in the opening scene of American Beauty describing the images of an American suburb the viewer sees onscreen. Or consider Tyler Durden (Brad Pitt) in Fight Club, who points to the flashing "cigarette burn mark" in the upper right corner of the screen while the unnamed narrator played by Edward Norton is explaining the process of changing reels in a movie projector. Even if they are fictional, and the real recipients are aware of their narratorial status via voice-overs, they are aware of a(n implicit) viewer's presence not only a listener's, therefore rhetorically they are capable of communicating through images, as it were: manipulating them from a visually not presented narrative frame (like Lester's narration) or documentary-like intrusion into (or recreation of) the diegesis (like Fight Club's narrator character). The embedded character narration necessarily remains verbal in the diegesis, and it is the film's narration that supports, completes or distorts it with extra dimensions. Which is why it is possible for cinematic narration not only to (as some say) "illustrate" their verbal account, but to extend it with additional meaning while still considering the characters as full value narrators, just as their literary counterparts. 


\section{Proving the Second Assumption}

It is best to focus on the above mentioned two assumptions, that both the character and the cinematic narration have their own rhetorical function, on the rhetorical level, and briefly examine the film from this aspect. I argued that character narrated sequences like my main example, with a strange surplus (in the rhetorical level) that cannot be attributed to the narrating character as an anthropomorphic entity inside the diegesis, should still be considered as an utterance of the character, but presented by a different medium, which is not a natural way of communication even for a fictional human being. By strange surplus I am mostly referring to the audiovisual dimension, whose presence and appearance as a flashback is an extrinsic rhetorical choice in itself. Characters like Johnny should still be regarded as narrators even if the film represents their narratorial activity in its own cinematic means. As it has been registered earlier, the cinematic narration duplicates the character's gesture of deception, therefore even if they are not aware of the audience and cannot manipulate the visuals, the audio or the editing, the film can be "truthful" to their intent. Theoretically, it is not impossible to assume a film where we can link almost every rhetorically meaningful element to the character narrator, even if it is certainly not the case with our lying character narrator. I should remark that Hitchcock's film is not the best example to illustrate the possible hierarchies between human and non anthropomorphic cinematic narrators because of its complex narrative situation: what most critics tend to neglect is that we are talking about an embedded narration and more than one diegetic level. For this reason, it is indeed necessary to pay attention to elements with a different rhetorical purpose from that of the character narrator. Chatman misunderstood the situation when he stated that there were two equal narrative instances in Stage Fright, Johnny and the cinematic narrator, and also when he used the movie to demonstrate that "it is the implied author who juxtaposes the two narrations of the story and 'allows' us to decide which is true" (Chatman 1990, 132). Chatman treats the scope and function of implied authors differently than the present paper. In Stage Fright, the cinematic narration inevitably frames the character's account, whose narration is always embedded as long as one postulates a non-anthropomorphic agency controlling the discourse of the film. There is no benefit of differentiating between this narrator's and the implied author's scope, function or power. Cinematic narration in the widest sense (the combined application of cinematic resources: as the apparatus, the choice of actors, the mise en scène, etc. which of course are not 
purely narrative but they are in the service of storytelling) is considered to be equivalent with the implied author's rhetorical activity.

Turim, in her book Flashbacks in Film (1989), explores the characteristics of the lying flashback to show how the movie tries to authenticate it in order to deceive the viewer. Although she does not say it explicitly, some of her arguments highlight the role of cinematic narration in the lie and it helps to prove its function in the understanding of the film.

The movie greatly relies on the mimetically motivated tradition that characters can lie verbally, but the images we see are objective and represent the truth. This tradition is confirmed by other flashbacks in the film, indeed, working this way. In other words, the big twist was based on the subversion of a cinematic code, which Johnny was certainly unaware of. In Turim's view, the function of the fantasy scene in the flashback when Johnny imagines the process carried out by the police, which actually turns out to be true, is to lay stress on the reliability of the thoughts and personality (in psychological, not ethical terms) of the character, so the more the viewers know what he really experienced, the less they will doubt the accuracy of his evocation of events. The joke in this narration is that the fantasy sequence inside the flashback could be more real and accurate than the flashback itself, although it clearly signals the difference of the ontological status between the two. The juxtaposition of imagination and memory with realistic visuals opposed to a kind of palimpsest images is undeniably an important factor that is outside Johnny's control.

According to Turim, because Johnny evokes events that took place in the theatre (the last scene of the flashback), where Eve, his listener had been already present, "his version is authenticated by her acceptance of the retelling" (Turim 1989, 167). This argument should be reconsidered. She states that the theatre scene is supposed to convince Eve about earlier events, to "paint the full picture" for her, but it is not a satisfying answer in every aspect. Johnny is telling a sequence of events to her of which she has already been a witness. Thus, the scene is highly redundant, mimetically flawed in the context of the communicative situation between the two characters. Although it is perfectly sensible and functional in terms of communication between the film and its audience because it reveals a key element in the plot, namely, how Johnny escaped from the immediate danger. It is a brief but meaningful digression showing us a rhetorical gesture in which the story of the character narrator is not supplemented by additional details but it exists for higher communicational purposes. 


\section{Focalization}

Anderson states that "in films that lie to or mislead the viewer, one character is almost always the explicit focalizer. If we take Johnny Cooper as an example, we would say that he relates his version of events to Eve Gill, while the cinematic narrator focalizes through him, presenting to the viewer what Johnny describes to Eve" (Anderson 2010, 89). Mentioning the term focalization is not a new development in this case, Turim has already used it in her book, saying "this 'lie' is not one told by the film directly [...] for the lying images are not claimed by an omniscient narration, but rather by a single character. The audience is led to ignore this difference, however, and in that sense the film plays a 'trick' on its spectators. This sleight of hand on the part of the film makes it an example of how focalization can be used as a crucial element of narrative" (Turim 1989, 165). Turim basically states that there is deceptive internal focalization where the subjective nature of the story is hidden by the objectively looking cinematic narration which focalizes the main character. Once the truth is spilled out, the viewer reinterprets the flashback as controlled by Johnny's character.

In my interpretation, just the opposite is true: the seemingly internally focalized sequence turns out to be in no correlation with the diegetic truth, and because of this, I want to challenge the application of this narratological term elaborated by Gérard Genette for the relationship between a narrator and a character, and not for that between two narrating instances or embedment. Genette introduces the term in order to avoid "a confusion between the question who is the character whose point of view orients the narrative perspective? and the very different question who is the narrator - or, more simply, the question who sees? and the question who speaks?" (Genette 1980, 186). But in film, it is not that easy to differentiate between sight (perception) and speech (the utterance of the narrator), as cinema basically tells through showing. ${ }^{4}$

4 As long as showing is a prerequisite of narration in cinema. The presentation of the filmic image is a primal stage of filmic articulation, which the so-called montage or editing is based on. My argument is entirely compatible with André Gaudreault's famous distinction between monstration and narration. In his essay, Narration and Monstration in Film he describes cinema as a medium utilizing two representational devices. The activity of monstration can be understood as the production of a micro-narrative within a single shot, the semiotic articulation between the frames that is always in a state of here and now, it is the illusion of presence and the present. On the other hand, the activity of narration as a second level of filmic articulation happens between shots and overwrites this illusion with the fragmentation of space-time. Nevertheless, it cannot function independently of monstration because "there is no possibility of opening a temporal gap, a breach within which the narrating instance could allow itself to 'reflect' upon the world it narrates" (Gaudreault 1987, 31-32). 
It can be acknowledged that because of the conventions of film there are multiple modes of representing subjectivity with different amounts of information: think about the difference of subjective camera ("point-of-view shot") and "over the shoulder shot," which is more like the vision of a third person. This visual difference in Johnny's flashback creates an ambiguous situation, in which we get a subjective account of events: we follow Johnny and functionally know as much as his character in the second degree narrative, while the objective camera establishes a certain sense of reliability, implying we are outside Johnny's subjective perception. The question is whether it is rhetorically meaningful if the viewer literally sees more or different things than Johnny? In Stage Fright, the relevant tool is not the difference between Johnny's and the audience's vision, but a more fundamental one: the choice of showing Johnny's lie in audiovisual terms.

It is the view of the present essay that in movies like Stage Fright or The Usual Suspects (Bryan Singer, 1995) (with another embedded lying narrator) cinematic narration is not focalizing the character narrator because it turns out that the presented scenes are not simply the character's viewpoint, subjective perception of the world, or experiences of the past. At one point, the viewer realizes that she saw something that never really happened in the fictional world, hence the sequence cannot be considered as a distortion or restriction of information (Genette 1980, 189) in the Genettian sense, but an extension of the diegesis: as another narrative level. That focalization in film can be an abstract concept not only based on the flow of sensual data but strongly determined by the narrative context is important because those who interpret Johnny as a focalized object (in Bal's terms ${ }^{5}$ ) may miss to see him as a narrator himself. Focalization in Hitchcock's lying flashback seems to make sense only if applied to the relation between the character narrator (situated in the embedding level) and himself as the embedded character. ${ }^{6}$ Regarding the lying Johnny, the cinematic narration of Stage Fright does not utilize him only as a character but as another narratorial instance. That his voice is literally muted and

5 Bal sees focalization as a dichotomic, subject-object relationship. There is always an agent, who is the focalizor, and a focalized object. The narration represents the object (it can be a story, a description, a characterization, basically every element of a text) as the focalizing subject perceives it (cf. Bal 2009, 107-119).

6 One could see the concept of focalization as a redundancy when used for narrators in any kind of autodiegesis. According to Genette, this type of narration should be called "prefocalized" because the character narrator (as a character of the discourse) is obliged to justify how he gained the presented information; therefore, focalization is not a choice but a requirement because it "submits a priori to a modal restriction, one that can be sidestepped only by an infraction, or a perceptible distortion” (Genette 1988, 78). 
his story is represented in other ways may be an unusual technique, but it should not confuse our critical acumen.

What is revealed in the sequence is not directly connected to his selfhood, personality, knowledge or memory but his agency as a mediator, his skills of intrigue. The cinematic narration does not represent or explore his perspective of the diegetic world he is living in but duplicating his rhetorical act, his intent of deception. Moreover, it is worth observing that most of the time the movie follows Eve's character: her knowledge is much closer to the viewer's knowledge than Johnny's. It is even possible to interpret the images of the flashback as Eve's vision of the story, thereby the viewer gets access to her imagination instead of Johnny's memories.

I did not talk about extreme cases of explicit contradictions in the story between the verbal and the visual channels (partly because there is no voice-over during most of the flashback) for I wanted to demonstrate more sophisticated ways of interactions that utilize the medial differences of linguistic and cinematic signs. Here, the character narration and the activity of an outside agent did not become incompatible, instead showed us the complexity a narrative film can accomplish.

\section{References}

Anderson, Emily R. 2010. Telling Stories: Unreliable Discourse, Fight Club, and the Cinematic Narrator. Journal of Narrative Theory vol. 40 no. 1: 80-107.

Booth, Wayne C. 1983 [1961]. The Rhetoric of Fiction. Chicago: University of Chicago Press.

Bal, Mieke. 2009 [1980]. Narratology: Introduction to the Theory of Narrative. Toronto, Buffalo and London: University of Toronto Press.

Bordwell, David. 1985. Narration in the Fiction Film. Madison: University of Wisconsin Press.

Branigan, Edward R. 1984. Point of View in the Cinema. A Theory of Narration and Subjectivity in Classical Film. Berlin: Mouton.

Burgoyne, Robert. 1990. The Cinematic Narrator: The Logic and Pragmatics of Impersonal Narration. Journal of Film and Video vol. 42 no. 1: 3-16.

Chatman, Seymour. 1980 [1978]. Story and Discourse: Narrative Structure in Fiction and Film. Ithaca: Cornell University Press.

Chatman, Seymour. 1990. Coming to Terms: The Rhetoric of Narrative in Fiction and Film. Ithaca: Cornell University Press. 
Currie, Gregory. 1995. Unreliability Refigured: Narrative in Literature and Film. The Journal of Aesthetics and Art Criticism vol. 53 no. 1: 19-29.

Fludernik, Monika. 1996. Towards a 'Natural' Narratology. London: Routledge.

Gaudreault, André. 1987. Narration and Monstration in Film. Journal of Film and Video vol. 39 no. 2: 29-36.

Genette, Gérard. 1980 [1972]. Narrative Discourse. An Essay in Method. Ithaca: Cornell University Press.

Genette, Gérard. 1988 [1983]. Narrative Discourse Revisited. Ithaca: Cornell University Press.

Mitchell, W. J. T. 1995 [1990]. Representation. In Critical Terms for Literary Study, eds. Frank Lentricchia and Thomas McLaughlin, 11-12. Chicago: University of Chicago Press.

Searle, John R. 1975. The Logical Status of Fictional Discourse. New Literary History vol. 6 no. 2: 319-332.

Turim, Maureen. 1989. Flashbacks in Film: Memory and History. New York: Routledge.

Walsh, Richard. 1997. Who is the Narrator? Poetics Today no. 4: 495-513.

Walsh, Richard. 2007. The Rhetoric of Fictionality: Narrative Theory and the Idea of Fiction. Columbus: The Ohio State University Press. 